\title{
Motor vehicle collisions caused by the 'super-strength' synthetic cannabinoids, MAM-2201, 5F-PB-22, 5F-AB-PINACA, 5F-AMB and 5F-ADB in Japan experienced from 2012 to 2014
}

\author{
Shuji Kaneko' ${ }^{1}$
}

Received: 11 May 2017/Accepted: 15 May 2017/Published online: 29 May 2017

(c) The Author(s) 2017. This article is an open access publication

\begin{abstract}
From 2012 to 2014 in Japan, 214 cases of motor vehicle collisions were attributed to the use of illegal drugs. In 93 out of 96 investigated cases, the causative agents were a variety of synthetic cannabinoids (SCs). These SCs can be classified into three groups according to the lineage of the chemical structures: (1) naphthoyl indoles, such as MAM-2201, (2) quinolinyl ester indoles, such as 5F-PB22 , and (3) indazole carboxamides, such as 5F-ABPINACA, 5F-AMB, and 5F-ADB. These SCs became available sequentially with increasing cannabinoid $\mathrm{CB}_{1}$ agonist potencies and reached a nationwide outbreak in the summer of 2014. They caused acute intoxication with impaired consciousness, anterograde amnesia (impaired memory), catalepsy with muscle rigidity, tachycardia, and vomiting or drooling soon after smoking. Drivers who had abused one of these SCs might unexpectedly experience the acute intoxication that caused uncontrolled driving. These SCs were generally difficult to detect from body fluid samples. It is thought that the highly lipophilic SCs disappear from the blood via rapid degradation by liver enzymes and selective accumulation into adipose tissues. Thus, much effort should be directed to the development of fast and sensitive chemical detection of the drug usage.
\end{abstract}

Keywords Synthetic cannabinoid - Motor vehicle collision · Catalepsy · Anterograde amnesia - Intoxication symptoms

Shuji Kaneko

skaneko@pharm.kyoto-u.ac.jp

1 Department of Molecular Pharmacology, Graduate School of Pharmaceutical Sciences, Kyoto University, YoshidaShimoadachi-cho 46-29, Sakyo-ku, Kyoto 606-8501, Japan

\section{Introduction}

Synthetic cannabinoids (SCs) are a diverse class of compounds that are designed to elicit selective agonist activities on cannabinoid $\mathrm{CB}_{1}$ and/or $\mathrm{CB}_{2}$ receptors. Originally, $\mathrm{SCs}$ were developed in an attempt to find potentially safer therapeutic agents. However, many SCs have recently emerged that possess new chemical structures, and are widely abused as recreational cannabis substitutes [1]. The outbreak of SCs has social ramifications, particularly relating to the increased number of motor vehicle accidents, which occur easily since SCs are inadvertently and handily used by drivers when they smoke herbal mixtures containing SCs. The hazardous effects on driving are evident from the inhibitory actions of SCs on the central nervous system, resulting in somnolence and retarded movements. In addition, other psychotropic and physical adverse effects of SCs [1,2] may be involved in causing motor vehicle accidents.

In Japan, 214 motor vehicle collisions were attributed to the use of illegal drugs from 2012 to 2014 (as announced in an official Japanese document from the National Police Agency). The number of suspected cases was 19 in 2012, 38 in 2013, and explosively increased to 157 in 2014. Accordingly, the Japanese Government has tightened the regulations on illegal drugs, and the outbreak has apparently been suppressed from 2015 to the present. The investigative organizations have provided the author with evidence on 96 serious cases that took place from 2012 to 2014. Most of the suspected compounds were SCs, although it was difficult to establish a causal relationship between drug use and an accident because of the lack of human toxicological or pharmacokinetic data on newly identified compounds. Moreover, only limited data were available for laboratory tests in these cases, because blood 
testing requires a court-issued warrant in Japan, which is difficult and time-consuming to obtain. However, the timeline of detected substances, drivers' statements, and observed symptoms were useful for a better understanding of the detrimental effects of SCs on driving. In this review, the author summarizes the toxicological features of recent 'super-strength' SCs by grouping compounds found in the 96 cases and highlighting typical accidents.

\section{Overview}

Table 1 summarizes the observational data on the 96 investigated cases. All accidents were caused by male drivers with an average age of 30.8 years, reflecting the distribution of illegal drug abusers in Japan. The accidents occurred mainly in metropolitan areas in 2012, but afterward spread to rural areas where automobiles are required for daily living. Four persons were killed in four tragic cases, and more than 110 persons were injured in 51 cases. The objective appearances of the drivers after the collision were collectively described as 'impaired consciousness' in 73 out of 96 cases $(76 \%)$, but excited states such as agitation, shouting, confusion, and continuous stereotyped behaviors were reported in 16 cases $(17 \%)$. The causative

Table 1 Overall characteristics of drug-induced motor vehicle collisions in the 96 investigated cases that occurred during 2012-2014 in Japan

\begin{tabular}{ll}
\hline Properties & $n$ \\
\hline Driver's gender & \\
Male & 96 \\
Female & 0 \\
Driver's age - Range 19-54 & 30.8 \\
Mean & 30 \\
Median & \\
Accident classification & 4 \\
Fatal & 51 \\
Injury & 41 \\
Property damage & \\
Appearance just after the collision & 73 \\
Impaired consciousness & 16 \\
Excited or confused & 7 \\
Unknown & \\
Used (or possessed) substances & 43 \\
One SC & 30 \\
Multiple SCs & 14 \\
SC + cathinones & 6 \\
SC + diphenidines & 3 \\
Diphenidines only & 0 \\
Cathinones only & \\
\hline SC syntheticannabinid & \\
\hline
\end{tabular}

$S C$ synthetic cannabinoid agents were mainly hypothesized to be chemical compounds detected in the drivers' belongings, such as pipes and herbal pieces. In 93 out of 96 cases, one or more SCs were found, sometimes in combination with cathinones or diphenidines. Only diphenidine or its derivative was detected in the remaining three cases. There was no case in which only cathinone derivatives were used. These results suggest that SCs were the primary cause of motor vehicle collisions in most of these cases.

However, only limited data were available about blood and urine concentrations of SCs in these cases (Tables 2 and 3), indicating that direct evidence of illegal SC use was obtained in only one third of all cases. Of the 20 cases in which SCs were used in combination with other psychostimulants, cathinones or diphenidines were detected in 12 cases, while SCs were identified in only five cases. These facts suggest the difficulty of detecting and profiling SCs in biological samples, because of the relatively small amount of intake, unknown metabolism, and possible instability in the human body.

\section{Lineage and timeline of SC}

Figure 1 shows the quarterly timeline of illegal compounds detected over 3 years. In total, ten cathinones, two diphenidines, and 22 SCs were identified. Assuming that SCs are the principal cause of impaired driving, the timeline can be divided into three sections according to the common structure of the prevalent SC:

(1) Until 2013 spring when naphthoyl indoles, such as MAM-2201, were dominant.

(2) Spring to winter 2013 when quinolinyl ester indoles, such as 5F-PB-22, were dominant.

(3) 2014 when indazole carboxamides, such as 5F-ABPINACA, became dominant.

Table 2 SCs identified in blood samples

\begin{tabular}{|c|c|c|}
\hline Name & $n$ & Concentration \\
\hline AM-2232 & 1 & N.Q. \\
\hline $5 F-P B-22$ & 6 & $\begin{array}{l}\text { Range } 0.274-0.93 \mathrm{ng} / \mathrm{mL}(n=5) \text {, median } \\
0.35 \mathrm{ng} / \mathrm{mL}\end{array}$ \\
\hline FUB-PB-22 & 4 & Range $0.79-1.74 \mathrm{ng} / \mathrm{mL}(n=2)$ \\
\hline NM-2201 & 1 & N.Q. \\
\hline AB-PINACA & 1 & $0.04 \mathrm{ng} / \mathrm{mL}$ \\
\hline NNE-1 & 1 & $2.3 \mathrm{ng} / \mathrm{mL}$ \\
\hline 5F-AB-PINACA & 1 & $0.16 \mathrm{ng} / \mathrm{mL}$ \\
\hline AB-FUBINACA & 1 & N.Q. \\
\hline $5 \mathrm{~F}-\mathrm{AMB}$ & 4 & $0.07 \mathrm{ng} / \mathrm{mL}(n=1)$ \\
\hline AB-CHMINACA & 4 & $1.3-31 \mathrm{ng} / \mathrm{mL}(n=3)$, median $2.7 \mathrm{ng} / \mathrm{mL}$ \\
\hline
\end{tabular}

N.Q. not quantified 
Table 3 SCs identified in urine samples

\begin{tabular}{ll}
\hline Name & $n$ \\
\hline FUB-PB-22 & 1 \\
NNE-1 & 1 \\
5F-AB-PINACA & 3 \\
5F-AMB & 7 \\
AB-CHMINACA & 3 \\
5F-ADB & 2 \\
\hline
\end{tabular}

The following chapters deal with the transition of SCs with reference to the 12 typical cases of accidents, in which observational consequences are well-documented and clearer than other cases (Table 4).

\section{MAM-2201 and naphthoyl indoles}

The first-generation SCs were naphthoyl indole derivatives, such as JWH-018, which are known as the main component of 'Spice' and 'K2' drugs [2, 3]. Some of these SCs have more potent affinity and efficacy than the natural cannabis ingredient $\Delta^{9}$-tetrahydrocannabinol (THC), enabling stronger in vivo pharmacodynamic effects at lower doses [1]. The classical naphthoyl indole SCs were banned oneby-one as 'designated substances' by the Pharmaceutical Affairs Act in Japan. Accordingly, more diverse derivatives, such as MAM-2201 and AM-2232 (Fig. 2a) had emerged by 2012 [4], thereby evading the regulations.

These new naphthoyl indole SCs were involved in ten cases of motor vehicle collisions, often in combination with cathinone stimulants. However, as seen in the typical cases 1 and 2 (Table 4), naphthoyl indole SCs elicited excitation behaviors by itself, as reported in an intoxicated patient with MAM-2201 [5].

The naphthoyl indole SCs were barely determined in blood samples and never detected in urine samples. This may be due to the following reasons: (1) rapid action and rapid disappearance from blood, as reported in a controlled administration study of JWH-018 [6]; (2) high lipophilicity, as shown by a fatal case in which MAM-2201 was concentrated in the adipose tissue [7]; (3) low dose, according to their strong potency. As for the $\mathrm{CB}_{1}$ agonistic potency of MAM-2201, the $\mathrm{IC}_{50}$ value in inhibiting excitatory synaptic transmission in mouse cerebellum was 2.5and 3-times lower than WIN-55,212 and JWH-018, respectively [8], demonstrating that MAM-2201 is stronger than the classical naphthoyl indoles. In addition, the mean concentration of MAM-2201 was reported to be $1.04 \mathrm{ng} / \mathrm{g}$ whole blood in Swedish recreational uses [9], indicating that only $2.8 \mathrm{nM}$ blood concentration is sufficient to elicit cannabis-mimetic actions.

These naphthoyl indole SCs were banned by the structure-based, inclusive regulation of 2013 spring, and they disappeared from the Japanese illegal market.

\section{F-PB-22 and its analogs}

Before the disappearance of naphthoyl indoles, a new type of SCs with quinolinyl ester indole and indazole
Fig. 1 Heat map of illegal drugs found in the investigated cases of motor vehicle collisions during 2012-2014 in Japan. $\alpha$ PHPs includes $\alpha$-PHP and its 4-fluoro derivative. $\alpha$-PHPPs includes $\alpha$-PHPP, its 4 -fluoro, and 4-methoxy derivatives. Diphenidines includes diphenidine and its 2-methoxy derivative. For the horizontal axis, the time span is indicated; for example, "12Q1" means the first quarter of 2012. The right vertical bar with different densities shows the number of cases

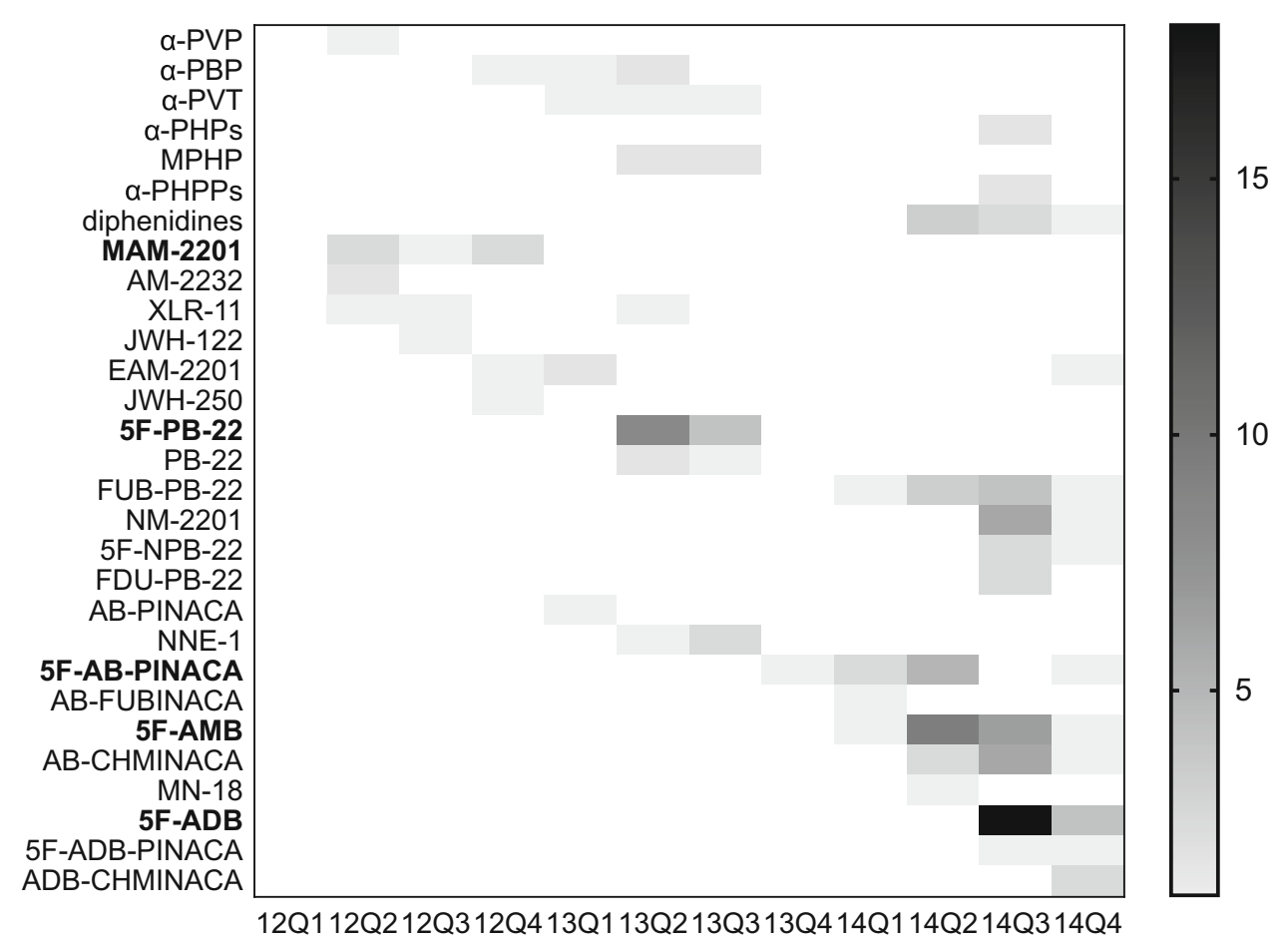


Table 4 Typical cases of SC-induced motor vehicle collisions

\begin{tabular}{|c|c|c|c|c|c|}
\hline Case & yymm & Age & Case history & Symptoms & Laboratory results \\
\hline 1 & 1205 & 25 & $\begin{array}{l}\text { A driver smoked 'Super Zeus' twice } \\
1.8 \mathrm{~km} \text { before the collision. The car } \\
\text { made a jump-start reaching } 114 \mathrm{~km} / \mathrm{h}\end{array}$ & $\begin{array}{l}\text { The driver had blurred vision and a dull } \\
\text { headache } 0.9 \mathrm{~km} \text { before the accident. } \\
\text { After the crash, he looked excited with }\end{array}$ & $\begin{array}{l}\text { MAM- } 2201 \text { and AM- } 2232 \text { were detected } \\
\text { in the herbal mixture. AM- } 2232 \text { was } \\
\text { detected from the blood sample }\end{array}$ \\
\hline
\end{tabular}
at a crossing on a red-light. Two cars were damaged, and 5 persons were injured

$2 \quad 1210 \quad 31 \quad$ A high school girl was hit by a car with her bicycle on a crosswalk and died. There was no sign of braking. The road was simply straight

$3 \quad 1304 \quad 41$ While driving a sports car, the driver smoked a pinch of herbal blend.Then 5-10 min later, the driver was alerted by a horn. After $5 \mathrm{~min}$, the car crashed into the narrow space between the leading vehicles. Five cars were damaged and six persons were injured

$4 \quad 1306 \quad 24 \quad$ Driver was a long-term abuser. On a onelane roadway, his car suddenly went straight into the opposite lane. Two cars suffered frontal collisions, and two persons were injured

$5 \quad 1309 \quad 38 \quad$ A driver had been using herbal drugs for two years. His car ran onto the sidewalk at a speed of $20 \mathrm{~km} / \mathrm{h}$ and hit 4 persons without braking herbal drug at a post office and immediately smoked in his car. Six minutes after smoking, his car went straight on a curve road at $36 \mathrm{~km} / \mathrm{h}$ and drove into the opposite lane. A child walking on the opposite sidewalk after the school was hit and the child died

Two persons smoked herbal drugs while driving a sports utility vehicle. When a police patrol car followed their car at a red crossing signal, the car suddenly ran away into the narrow space between the leading vehicles. Ten cars were damaged and 12 persons were injured

A driver was a long-term abuser. $\mathrm{He}$ ignored a red light at $80 \mathrm{~km} / \mathrm{h}$ and caused successive vehicle collisions. Eight persons were injured

Two persons took turns smoking herbal blends while driving. At a crossing, the car suddenly jump-started into the opposite lane, reaching $100 \mathrm{~km} / \mathrm{h}$. The car drove more than $100 \mathrm{~m}$ and caused several head-on crashes one after another. One young man was killed and two persons were injured

$10 \quad 1406 \quad 37 \quad$ On a busy downtown street, a car drove on a wide sidewalk for $30 \mathrm{~m}$ and hit many walkers one after another until it was stopped by collision with a telephone booth. One young lady was killed and seven persons were injured abnormal postures. Driver had no memory of the crash

The driver confessed to the use of a herbal mixture while driving. He had a reddened face, looked agitated, and then ran away from inspection

The driver looked emotionless. He kept flooring the accelerator pedal even after the crash, and the tires were melted down. Driver had no memory of the crash

Driver lost consciousness. His eyes rolled up, and he made groaning sounds. Driver recovered after $3.5 \mathrm{~h}$, but had no memory of the crash

Even after the crash, the driver did not step off the accelerator pedal, but kept on moving the steering wheel and gear lever in a stereotyped manner. Driver had no memory of abnormal driving

The driver kept grasping the steering wheel and did not respond to bystanders' shouts. Driver had no interest in the car crash. Emergency crew identified traces of vomiting. After $25 \mathrm{~min}$, the driver recovered and could walk by himself. He had no memory of the crash

The driver exhibited impaired consciousness with slow movements. His reaction turned to 'crazy' excitation and agitation during inspection by police. Driver had no memory of the crash but could recall the place of smoking

The driver was awake but motionless, and he did not respond for $10 \mathrm{~min}$. He started moving 15 min after the crash and responded by talking thereafter. Driver had no memory of the crash

Driver exhibited impaired consciousness with drooling and a heart rate of 123 beats/min. Driver had no memory of the jump-start but he remembered smoking. The passenger ran away

Driver lost consciousness and was drooling. He had no memory of what occurred after smoking
MAM-2201 was detected in the herbal mixture

5F-PB-22 and PB-22 were detected in the herbal material. Blood and urine samples were not taken

5F-PB-22 $(0.274 \mathrm{ng} / \mathrm{mL})$ was detected in the blood sample taken 45 min after the car crash

5F-PB-22 and NNE-1 were detected in the herbal material. Blood was sampled $17 \mathrm{~h}$ after the crash, and $0.39 \mathrm{ng} / \mathrm{mL}$ 5F-PB-22 was detected

5F-AB-PINACA was detected in the herbal mixture, but not in the blood sample taken after $49 \mathrm{~h}$ after the crash

FUB-PB-22 $(1.74 \mathrm{ng} / \mathrm{mL})$ was detected from a blood sample taken $75 \mathrm{~min}$ after the crash. In addition, 5F-AMB, THJ2201, and AMB were detected in the herbal mixture

5F-AMB was detected in the herbal mixture and in the blood sample taken $14 \mathrm{~h}$ after the crash (but was not quantified)

$5 \mathrm{~F}-\mathrm{AMB}$ was detected in urine samples of the driver and passenger

5F-AMB and AB-CHMINACA were detected in the herbal mixture. In addition, 5F-AB-PINACA was detected in the urine sample 
Table 4 continued

\begin{tabular}{|c|c|c|c|c|c|}
\hline Case & yymm & Age & Case history & Symptoms & Laboratory results \\
\hline 11 & 1407 & 26 & $\begin{array}{l}\text { An unlicensed driver smoked while } \\
\text { driving. Five minutes later, his car } \\
\text { began weaving and was accelerated to } \\
80 \mathrm{~km} / \mathrm{h} \text {. The car successively hit a } \\
\text { motorbike and several cars, and it was } \\
\text { stopped by collision with a lamppost on } \\
\text { the sidewalk. Three persons were } \\
\text { injured. The entire proceeding was } \\
\text { recorded in a dashboard camera }\end{array}$ & $\begin{array}{l}\text { Driver was found wandering around the } \\
\text { car with impaired consciousness. He } \\
\text { had no memory of driving from } 2 \mathrm{~min} \\
\text { before the car started weaving }\end{array}$ & $\begin{array}{l}\text { 5F-AMB }(0.07 \mathrm{ng} / \mathrm{mL}) \text { and FUB-PB-22 } \\
(0.79 \mathrm{ng} / \mathrm{mL}) \text { were detected in the } \\
\text { blood sample taken } 10 \mathrm{~h} \text { after the } \\
\text { crash. In the urine, } 5 \mathrm{~F}-\mathrm{AMB} \text { and THC } \\
\text { were detected }\end{array}$ \\
\hline 12 & 1409 & 30 & $\begin{array}{l}\text { The driver was a long-term abuser for } \\
\text { more than } 3 \text { years and never } \\
\text { experienced memory loss. However, } \\
\text { after a brief smoking of 'Heart Shot } \\
\text { Red', he lost memory. Within } 5 \text { min, } \\
\text { his car crashed into a parked car }\end{array}$ & $\begin{array}{l}\text { Driver lost consciousness, but recovered } \\
\text { within an hour. He had a heart rate of } \\
106 \text { beats/min with tachypnea } 13 \mathrm{~min} \\
\text { after the crash }\end{array}$ & $\begin{array}{l}\text { 5F-ADB was detected in the urine, saliva } \\
\text { and hair. } 4 \mathrm{~F}-\alpha-\mathrm{PHPP} \text { was detected in } \\
\text { the blood }\end{array}$ \\
\hline
\end{tabular}

yymm first two figures show the year and last two the month

carboxamide backbone structures emerged [10]. Among them, 5F-PB-22 (Fig. 2b) was involved in all 15 cases during the half-year from April to September 2013 until it was banned as a designated substance.

5F-PB-22 was 100 and 36 times more potent than WIN55,212 and JWH-018, respectively, in a functional agonist assay using recombinant human $\mathrm{CB}_{1}$ receptor [11]. A longterm abuser who had been accustomed to naphthoyl indole SCs might become easily intoxicated after routine smoking of herbal blends containing the new ingredient that was stronger than before, as seen in the cases 3, 4, and 5 (Table 4). Catalepsy with muscle rigidity was the characteristic acute symptom in these cases, which may be the direct cause of accidents.

5F-PB-22 was detected from blood samples in six cases, and could be determined in five cases with a range of $0.274-0.93 \mathrm{ng} / \mathrm{mL}$ (Table 2). The average concentration of $0.45 \mathrm{ng} / \mathrm{mL}$ is equivalent to $1.2 \mathrm{nM}$, suggesting its strong toxicity. In four postmortem cases, the observed concentration range of 5F-PB-22 was $1.1-1.5 \mathrm{ng} / \mathrm{mL}$ [12], indicating that the toxic dose for driving is close to the lethal dose. Because 5F-PB-22 is highly lipophilic, and the predominant metabolic pathway of 5F-PB-22 in human hepatocytes is ester hydrolysis yielding a wide variety of metabolites [13], it is difficult to identify its unchanged form or metabolites in urine. Indeed, 5F-PB-22 was never detected in urine samples.

After 5F-PB-22 was banned, several derivatives of 5FPB-22, such as FUB-PB-22 and NM-2201 (Fig. 2b) appeared and were used in 2014. Although these SCs were involved in a number of cases (Fig. 1), including cases 7 and 11 (Table 4), their pharmacodynamic and pharmacokinetic data are currently unavailable.

\section{F-AB-PINACA, 5F-AMB and their analogs}

From the end of 2013, SCs with indazole carboxamide backbones have become predominant (Fig. 2c). This type of SCs was the strongest $\mathrm{CB}_{1}$ agonist and seemed to be designed and modified according to a patent applied by Pfizer [14].

5F-AB-PINACA was involved in 11 cases from 2013 December to 2014 April until it was banned. 5F-ABPINACA is 38 and 360 times more potent than JWH-018 and THC, respectively, in a functional agonist assay using recombinant human $\mathrm{CB}_{1}$ receptor [15]. Accordingly, as seen in case 6 (Table 4), use of 5F-AB-PINACA while driving caused abrupt intoxication accompanied by catalepsy, vomiting, and loss of consciousness. Later, ABCHMINACA, a similar compound with a cyclohexyl ring, appeared and was involved in 11 cases.

A nationwide outbreak of SC use occurred in the summer of 2014 with 5F-AMB and 5F-ADB featuring L-valinate and L-tert-leucinate, respectively, in the pendant group (Fig. 2c). 5F-AMB and 5F-ADB are 90 and 300 times, respectively, more potent than THC as full agonists for the human $\mathrm{CB}_{1}$ receptor [16].

$5 \mathrm{~F}-\mathrm{AMB}$ was involved in 21 cases, including several tragic collisions such as cases $8-11$ (Table 4). In serious cases, catalepsy was accompanied by muscle rigidity in the extremities, which provoked abrupt acceleration of the car without braking or controlling the steering wheel. Catalepsy is characterized in rodents as prolonged motionless at unnatural posturing and known as one of the tetrad of cannabinoid actions together with lowered body temperature, antinociception, and decreased spontaneous locomotion. These symptoms were also observed when mice were 
a



b

$5 F-P B-22$

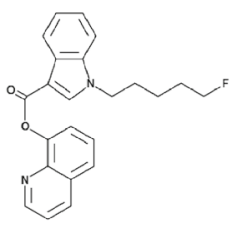

FUB-PB-22

NM-2201

C
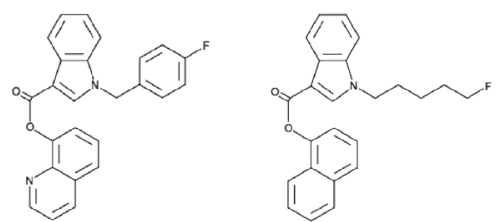

5F-AB-PINACA

AB-CHMINACA


$5 \mathrm{~F}-\mathrm{AMB}$

$5 F-A D B$
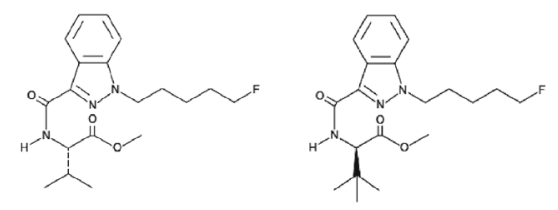

Fig. 2 Frequently-used synthetic cannabinoids with a naphthoyl indole, b quinolinyl ester indole, and $\mathbf{c}$ indazole carboxamide backbones

injected with AB-CHMINACA or AB-PINACA [17]. The rodent catalepsy recovers by external stimulus such as airpuff or sound, and they were reportedly mediated by decreased 5-HT transmission in the basal ganglia [18]. In contrast, in humans, strong SCs causes more severe, irreversible catalepsy with muscle rigidity, high body temperature, tachycardia, and vomiting. As these symptoms resemble the serotonin syndrome, the author and colleagues investigated the effect of $5 \mathrm{~F}-\mathrm{ADB}$ on midbrain serotonergic neurons. However, 5F-ADB did not affect serotonergic activity; rather, dopaminergic firings were readily increased [19]. Therefore, the neuronal mechanism underlying catalepsy seen in SC abuser is unclear.

The 'final boss' 5F-ADB was detected in the most frequent 24 cases, but fortunately, without a serious case. This may be because too much 5F-ADB was added to the herbal products, and drivers could not drive very far after smoking before losing consciousness, as seen in case 12 (Table 4). Accordingly, vomiting or a trace of vomiting was frequently observed in impaired drivers in 14 out of 23 cases involving 5F-ADB. It is also known that many people died in 2014 by smoking herbal products containing excess amounts of 5F-ADB (unpublished observation). Many news reports showing the dangerous effects of illegal drugs also helped to suppress the recreational uses. All these SCs were banned by the end of 2014 .

An apparent difference in the action of this class of SCs was the time required for recovery from impaired consciousness. Users of naphthoyl indoles and quinolinyl ester indoles required more than an hour to communicate normally with other persons. However, drivers taking indazole carboxamide SCs frequently showed rapid recovery within an hour. It has been reported that $5 \mathrm{~F}-\mathrm{AMB}$ is quickly hydrolyzed by hepatic esterase [20], while 5F-ABPINACA is more slowly metabolized to various products [21]. The rapid recovery seen in this class of SC remains mysterious.

Another characteristic of indazole carboxamide SCs is the detection from urine samples (Table 3). Increased polarity of the chemical structures may have contributed to the solubility of the compounds in aqueous solution. However, detection from blood samples was rare in this class of SC because the low dose and fast metabolism made the concentration in blood undetectable.

In a series of studies analyzing indazole carboxamide SCs in remaining human cadavers [22-24], 5F-AMB was mostly concentrated in the adipose tissue, while 5F-ADB and $\mathrm{AB}-\mathrm{CHMINACA}$ were more widely distributed in other organs, such as brain and heart muscles. These SCs were never detected in the blood and urine, whereas MABCHMINACA (also called ADB-CHMINACA) was present in the blood as much as in other organs, although not in the urine. The mechanisms underlying distribution, metabolism, and excretion of SCs may be diverse and need to be investigated individually in detail.

\section{Concluding remarks}

The most striking and almost common statements of SCabused drivers are that they did not remember the collision scene, including before and after, although there may be some doubt on the drivers' statements in themselves. The driver could drive properly (to some extent) with his eyes open while he could not remember what he was doing prior to the collision, suggesting that use of SCs caused anterograde amnesia that disabled new learning.

Most drivers seemed to be accustomed to using illegal drugs on some level and routinely used SC products while driving. However, the quality control of illegal products is so inaccurate and inconsistent that some packages might contain a huge amount of $\mathrm{SC}$, as reported in the case of 5FADB [23], which might cause unexpected intoxication in a driver, instantly leading to uncontrolled driving. 
Because the clinical signs observed in the abused drivers are transient in conjunction with the disappearance of active compounds from the body fluid, prosecution cannot be solely based on the material evidence. Much effort should be directed to the development of fast and sensitive chemical detection of drug usage.

The outbreak of SC is just like cyber-terrorism, wherein a wise scientist turns into a smart evil one. Given that the science extends its capability infinitely, we must keep in mind that there may be another outbreak of different kinds of illegal drugs.

Acknowledgements The article processing charge for Open Access is supported by Grant-in-Aid (Grant Number: 15HP2018) from the Japan Society for the Promotion of Science, through the Japanese Association of Forensic Toxicology.

\section{Compliance with ethical standards}

Conflict of interest Author Shuji Kaneko declares that he has no conflict of interest.

Ethical approval This article does not contain any studies with human participants performed by the author.

Open Access This article is distributed under the terms of the Creative Commons Attribution 4.0 International License (http://crea tivecommons.org/licenses/by/4.0/), which permits unrestricted use, distribution, and reproduction in any medium, provided you give appropriate credit to the original author(s) and the source, provide a link to the Creative Commons license, and indicate if changes were made.

\section{References}

1. Castaneto MS, Gorelick DA, Desrosiers NA, Hartman RL, Pirard S, Huestis MA (2014) Synthetic cannabinoids: epidemiology, pharmacodynamics, and clinical implications. Drug Alcohol Depend 144:12-41

2. Seely KA, Lapoint J, Moran JH, Fattore L (2012) Spice drugs are more than harmless herbal blend: a review of the pharmacology and toxicology of synthetic cannabinoids. Prog Neuropsychopharmacol Biol Psychiatry 39:234-243

3. Gunderson EW, Haughey HM, Ait-Daoud N, Joshi AS, Hart CL (2012) "Spice" and "K2" herbal sighs: a case series and systematic review of the clinical effects and biopsychosocial implications of synthetic cannabinoid use in humans. Am J Addict 21:320-326

4. Uchiyama N, Kawamura M, Kikura-Hanajiri R, Goda Y (2013) URB-754: a new class of designer drug and 12 synthetic cannabinoids detected in illegal products. Forensic Sci Int 227:21-32

5. Derungs A, Schwaninger AE, Mansella G, Bingisser R, Kraemer T, Liechti ME (2013) Symptoms, toxicities, and analytical results for a patient after smoking herbs containing the novel synthetic cannabinoid MAM-2201. Forensic Toxicol 31:163-171

6. Teske J, Weller JP, Fieguth A, Rothämel T, Schulz Y, Tröger HD (2010) Sensitive and rapid quantification of the cannabinoid receptor agonist naphthalen-1-yl-(1-pentylindol-3-yl)methanone (JWH-018) in human serum by liquid chromatography-tandem mass spectrometry. J Chromatogr B 878:2659-2663
7. Saito T, Namera A, Miura N, Ohta S, Miyazaki S, Osawa M, Inokuchi S (2013) A fatal case of MAM-2201 poisoning. Forensic Toxicol 31:333-337

8. Irie T, Kikura-Hanajiri E, Usami M, Uchiyama N, Goda Y, Sekino Y (2015) MAM-2201, a synthetic cannabinoid drug of abuse, suppresses the synaptic input to cerebellar Purkinje cells via activation of presynaptic $\mathrm{CB}_{1}$ receptors. Neuropharmacology 95:479-491

9. Kronstrand R, Roman M, Anderson M, Eklund A (2013) Toxicological findings of synthetic cannabinoids in recreational users. J Anal Toxicol 37:534-541

10. Uchiyama N, Matsuda S, Kawamura M, Kikura-Hanajiri R, Goda Y (2013) Two new-type cannabimimetic quinolinyl carboxylates, QUPIC and QUCHIC, two new cannabimimetic carboxamide derivatives, ADB-FUBINACA and ADBICA, and five synthetic cannabinoids detected with a thiophene derivative $\alpha$-PVT and an opioid receptor agonist AH-7921 identified in illegal products. Forensic Toxicol 31:223-240

11. Banister SD, Stuart J, Kevin RC, Edington A, Longworth M, Wilkinson SM, Beinat C, Buchanan AS, Hibbs DE, Glass M, Connor M, McGregor IS, Kassiou M (2015) Effects of bioisosteric fluorine in synthetic cannabinoid designer drugs JWH-018, AM-2201, UR-144, XLR-11, PB-22, 5F-PB-22, APICA, and STS-135. ACS Chem Neurosci 6:1445-1458

12. Wohlfarth A, Gandhi AS, Pang S, Zhu M, Scheidweiler KB, Huestis MA (2014) Metabolism of synthetic cannabinoids PB-22 and its 5-fluoro analog, 5F-PB-22, by human hepatocyte incubation and high-resolution mass spectrometry. Anal Bioanal Chem 406:1763-1780

13. Behonick G, Shanks KG, Firchau DJ, Mathur G, Lynch CF, Nashelsky M, Jaskierny DJ, Merouch C (2014) Four postmortem case reports with quantitative detection of the synthetic cannabinoid 5F-PB-22. J Anal Toxicol 38:559-562

14. Buchler IP, Hayes MJ, Hegde SG, Hockerman SL, Jones DE, Kortum SW, Rico JG, Tenbrink RE, Wu KK (2009) Indazole derivatives as $\mathrm{CB}_{1}$ receptor modulators and their preparation and use in the treatment of $\mathrm{CB}_{1}$-mediated diseases. Patent WO/2009/ 106982

15. Banister SD, Moir M, Stuart J, Kevin RC, Wood KE, Longworth M, Wilkinson SM, Beinat C, Buchanan AS, Glass M, Connor M, McGregor IS, Kassiou M (2015) Pharmacology of indole and indazole synthetic cannabinoid designer drugs AB-FUBINACA, ADB-FUBINACA, AB-PINACA, ADB-PINACA, 5F-ABPINACA, 5F-ADB-PINACA, ADBICA, and 5F-ADBICA. ACS Chem Neurosci 6:1546-1559

16. Banister SD, Longworth M, Kevin R, Sachdev S, Santiago M, Stuart J, Mack JBC, Glass M, McGregor IS, Connor M, Kassiou M (2016) Pharmacology of valinate and tert-leucinate synthetic cannabinoids 5F-AMBICA, 5F-AMB，5F-ADB, AMB-FUBINACA, MDMB-FUBINACA, MDMB-CHMICA, and their analogues. ACS Chem Neurosci 7:1241-1254

17. Wiley JL, Marusich JA, Lefever TW, Antonazzo KR, Wallgren MT, Cortes RA, Patel PR, Grabenauer M, Moore KN, Thomas BF (2015) AB-CHMINACA, AB-PINACA and AB-FUBIMINA: affinity and potency of novel synthetic cannabinoids in producing $\Delta \Delta^{9}$-tetrahydrocannabinol-like effects in mice. J Pharmacol Exp Ther 354:328-339

18. Sano K, Mishima K, Koushi E, Orito K, Egashira N, Irie K, Takasaki K, Katsurabayashi S, Iwasaki K, Uchida N, Egawa T, Kitamura Y, Nishimura R, Fujiwara M (2008) $\Delta^{9}$-Tetrahydrocannabinol-induced catalepsy-like immobilization is mediated by decreased 5-HT neurotransmission in the nucleus accumbens due to the action of glutamate-containing neurons. Neuroscience $151: 320-328$

19. Asaoka N, Kawai H, Nishitani N, Kinoshita H, Shibui N, Nagayasu K, Shirakawa H, Kaneko S (2016) A new designer 
drug 5F-ADB activates midbrain dopaminergic neurons but not serotonergic neurons. J Toxicol Sci 41:813-816

20. Andersson M, Diao X, Wohlfarth A, Scheidweiler KB, Huestis MA (2016) Metabolic profiling of new synthetic cannabinoids $\mathrm{AMB}$ and 5F-AMB by human hepatocyte and liver microsome incubations and high-resolution mass spectrometry. Rapid Commun Mass Spectrom 30:1067-1078

21. Wohlfarth A, Castaneto MS, Zhu M, Pang S, Scheidweiler KB, Kronstrand R, Huestis MA (2015) Pentylindole/pentylindazole synthetic cannabinoids and their 5-fluoro analogs produce different primary metabolites: metabolite profiling for AB-PINACA and 5F-AB-PINACA. AAPS J 17:660-677

22. Hasegawa K, Wurita A, Minakata K, Gonmori K, Nozawa H, Yamagishi I, Watanabe K, Suzuki O (2015) Postportem distribution of AB-CHMINACA, 5-fluoro-AMB, and diphenidine in body fluids and solid tissues in a fatal poisoning case: usefulness of adipose tissue for detection of the drugs in unchanged forms. Forensic Toxicol 33:45-53

23. Hasegawa K, Wurita A, Minakata K, Gonmori K, Yamagishi I, Nozawa H, Watanabe K, Suzuki O (2015) Identification and quantification of 5-fluoro-ADB, one of the most dangerous synthetic cannabinoids, in the stomach contents and solid tissues of a human cadaver and in some herbal products. Forensic Toxicol $33: 112-121$

24. Hasegawa K, Wurita A, Minakata K, Gonmori K, Nozawa H, Yamagishi I, Watanabe K, Suzuki O (2015) Postportem distribution of MAB-CHMINACA in body fluids and solid tissues of a human cadaver. Forensic Toxicol 33:380-387 